\title{
ANALISIS USAHA TANI LADA DAN ARAHAN PENGEMBANGANNYA DI KABUPATEN BANGKA TENGAH
}

\author{
Farming Analysis and Development of Pepper in District of Bangka \\ Tengah
}

\author{
Maryadi $^{1}$, Atang Sutandi ${ }^{2}$, Ivanovich Agusta ${ }^{3}$
}

Diterima: 22 Oktober 2015 Disetujui: 4 April 2016

\begin{abstract}
Abstrak: Indonesia merupakan penghasil lada nomor dua di dunia setelah Vietnam. Lada adalah salah satu komoditi unggulan sebagai sumber devisa, sumber pendapatan petani, dan dapat menciptakan lapangan kerja. Tingginya permintaan pasar internasional terhadap lada merupakan peluang untuk pengembangan lada. Di Indonesia, Provinsi Bangka Belitung adalah produsen utama lada putih yang mana salah satu daerah penghasilnya adalah Kabupaten Bangka Tengah. Upaya pengembangan tanaman lada harus berdasarkan evaluasi kesesuaian lahan untuk produksi yang optimal. Selain itu, menganalisis kelayakan usaha tani lada, menganalisis marjin pemasaran dalam sistem pemasaran lada putih, dan menyusun arahan pengembangan perkebunan lada diperlukan sebagai pedoman pemangku kebijakan di Kabupaten Bangka Tengah. Pengembangan lada membutuhkan komitmen dan upaya yang didasarkan pada kebijakan pembangunan perkebunan yang dilaksanakan secara proporsional dan profesional.
\end{abstract}

Kata kunci: arahan pengembangan, kelayakan usaha, kesesuaian lahan, lada, marjin pemasaran

Abstract: Indonesia is the producer of pepper number two in the world after Vietnam. Pepper is one of the leading commodity that has a major role as source of foreign exchange, the source of farmer's income, and job creation. The high demand on the international market is an opportunity for the development of pepper pepper. In Indonesia, Bangka Belitung Province is a major producer of white pepper which one is the producing regions of District of Bangka Tengah. The development effort pepper plants must be based on land suitability evaluation for optimal production. Moreover, analyzing the feasibility of farming of pepper, analyze marketing margins in the marketing system of white pepper, and arrange referrals pepper plantation development is needed to guide policy makers in Central Bangka Regency. Pepper development requires commitment and effort which is based on plantation development policies implemented proportionately and professionally .

Keywords: pepper, direction of development, land suitability, marketing margins, the feasibility of farming

${ }^{1}$ Dinas Pertanian Perkebunan dan Peternakan, Provinsi Kep. Bangka Belitung

${ }^{2}$ Departemen Ilmu Tanah dan Sumberdaya Lahan Institut Pertanian Bogor

${ }^{3}$ Departemen Sains Komunikasi dan Pengembangan Masyarakat Institut Pertanian Bogor

Korespondensi: maryadilatief@gmail.com 


\section{PENDAHULUAN}

Komoditi lada putih dari Indonesia untuk pasar internasional sudah terkenal sejak dulu, yaitu Lada Putih Bangka (Muntok White Pepper), sedangkan untuk lada hitam yaitu komoditi Lada Hitam Lampung (Lampong Black Pepper). Komoditi Muntok White Pepper menjadi brand image yang terkenal di perdagangan internasional karena cita rasanya yang khas dengan rasa yang lebih pedas, artinya kualitas lada putih di pasar internasional selalu mengacu pada kualitas Lada Putih Bangka. Lada Putih Bangka juga sudah memiliki sertifikat Indikasi Geografis (IG) dari Kementerian Hukum dan HAM Republik Indonesia.

Provinsi Kepulauan Bangka Belitung merupakan penghasil dan pengekspor utama komoditi lada putih di Indonesia. Harga lada putih terus meningkat sesuai dengan permintaan negara tujuan ekspor seperti dari Eropa, Amerika Serikat, Singapura, Jepang dan negara lainnya. Menurut IPC (2013), ekspor lada putih Indonesia tertinggi terjadi pada tahun 2000, yaitu 63.938 ton (37\% dari total ekspor dunia) di mana 34.256 ton atau 53,6\%nya merupakan lada putih asal Bangka Belitung. Di dalam negeri, dengan konsumsi lada 60 gram/kapita/tahun artinya dalam setahun dibutuhkan 13.200 ton lada (Yuhono 2007). Perkembangan luas areal pertanaman lada selama beberapa tahun terakhir pada dasarnya merupakan respon masyarakat terhadap harga jual komoditi lada putih di pasar domestik yang telah terintegrasi dengan harga pasar dunia. Tingginya respon masyarakat untuk kembali mengusahakan lada merupakan sebuah peluang yang harus ditangkap dan dimaksimalkan oleh pengambil kebijakan.

Kabupaten Bangka Tengah merupakan salah satu daerah produsen lada di wilayah Provinsi Kepulauan Bangka Belitung. Pada tahun 2014 daerah ini memiliki luas areal perkebunan rakyat sebesar 19.278 hektar, dengan luas areal perkebunan lada 2.613 hektar atau sekitar $13 \%$ dari total areal perkebunan selain karet, kelapa sawit, dan tanaman perkebunan lainnya (Disbunhut Kab. Bangka Tengah 2014). Memperhatikan potensi yang ada dan prospek masa depan, komoditi lada putih tetap menjadi komoditi unggulan di Provinsi Kepulauan Bangka Belitung dan di Kabupaten Bangka Tengah khususnya yang berpotensi untuk terus dikembangkan dalam rangka pengembangan wilayah.

Pada awal diterbitkannya kebijakan mengenai dibolehkannya masyarakat ikut menambang mineral timah (Tambang Inkonvensional), hingga tahun 2012 roda perekonomian Kabupaten Bangka Tengah sangat dipengaruhi oleh sektor pertambangan. Rata-rata uang yang beredar dari aktivitas perdagangan timah mencapai Rp 2,8 triliun yang artinya secara virtual masyarakat Kabupaten Bangka Tengah memperoleh tambahan pendapatan Rp 17 juta per jiwa setiap tahunnya. Pada tahun 2013 saat kandungan timah menipis dan berakhirnya kontrak karya PT. Koba Tin yang berada di Kabupaten Bangka Tengah, pendapatan rata-rata menjadi Rp 11 juta per jiwa (Distamben Kab. Bangka Tengah 2014). Keadaan tersebut membuat masyarakat beralih kembali ke mata pencaharian sebagai petani lada.

Data yang bersumber dari BPS Kabupaten Bangka Tengah 2013 tercatat sebanyak $29,50 \%$ bekerja di sektor pertanian atau nomor 2 setelah sektor pertambangan $(31,42 \%)$. Komoditi lada putih bagi Kabupaten Bangka Tengah memiliki peranan penting dalam menggerakkan perekonomian Kabupaten Bangka Tengah. Rata-rata peredaran uang dari hasil perdagangan lada putih sebesar Rp 71 miliar per tahun. Jumlah tersebut dibandingkan dengan populasi penduduk berarti memiliki andil sebesar Rp 430.000 pada pendapatan per kapita atau bisa memberi pendapatan rata-rata Rp 19.700 .000 per petani lada setiap tahunnya. Membandingkan keadaan pada saat perekonomian bergantung pada timah dan pasca timah, terjadi kehilangan pendapatan sebesar Rp 5,5 juta per jiwa.

Permasalahan yang ada dalam pengembangan perkebunan lada rakyat di Kabupaten Bangka Tengah adalah rendahnya produktivitas lada, belum efisiennya sistem pemasaran komoditi lada putih di tingkat petani, keterbatasan modal untuk memperoleh bibit unggul 
dan sarana produksi lainnya. Belum berkembangnya peningkatan nilai tambah berupa produk olahan juga menyebabkan rendahnya pendapatan petani. Menurut Evalia et.al (2012), peningkatan nilai tambah terhadap suatu komoditas mampu meningkatkan pendapatan pada banyak sektor agribisnis. Semakin menipisnya kandungan logam timah di Pulau Bangka, khususnya di Bangka Tengah dan membaiknya harga komoditi lada putih membuat masyarakat Bangka Tengah kembali ke mata pencaharian yang sudah turun temurun digeluti yaitu berkebun lada. Tentunya hal ini harus menjadi perhatian agar petani tidak asal memilih lokasi yang akan menyebabkan berkurangnya keuntungan atau malah menderita kerugian.

Hasil penelitian Daras dan Pranowo (2009) menyimpulkan bahwa penurunan luas areal pertanaman lada disebabkan oleh faktor fluktuasi harga lada, gangguan OPT, dampak penambangan timah ilegal, dan introduksi tanaman perkebunan lainnya. Solusi alternatif yang ditawarkan untuk mengatasi permasalahan tersebut adalah berupa pewilayahan komoditas, diversifikasi usaha tani, penataaan tata niaga, serta penguatan modal dan kelembagaan usaha tani. Kemala (2011) melakukan penelitian mengenai strategi pengembangan agribisnis lada untuk meningkatkan pendapatan petani, memberikan gambaran akan berbagai persoalan yang dihadapi petani lada baik pada subsistem hulu maupun subsistem hilir. Penelitian ini memberikan berbagai strategi pemecahan masalah meliputi pentingnya membangun kebun bibit untuk penangkaran lada, pengembangkan pusat pertumbuhan lada berdasarkan keunggulan komparatif dan kompetitif wilayah serta penguatan kelembagaan dan teknologi.

Arahan dan analisis usaha tani lada sangat diperlukan untuk pengembangan perkebunan lada rakyat di Kabupaten Bangka Tengah sebagai upaya mengembalikan kejayaan Lada Putih Bangka di pasar internasional yang tentunya berdampak positif dengan peningkatan kesejahteraan masyarakat. Menurut Indraningsih (2013), dalam penentuan komoditi, ketersediaan sumberdaya (lahan, tenaga kerja, modal) merupakan faktor yang penting menunjang kinerja usaha tani. Selain itu, kemampuan bersaing melalui proses produksi yang efisien merupakan landasan utama bagi kelangsungan kegiatan usaha tani, terutama bila dikaitkan dengan orientasi usaha yang komersial. ). Selanjutnya Setianto dan Susilowati (2014) menyatakan bahwa arahan pengembangan komoditas perkebunan diprioritaskan sesuai dengan agroklimat, masih tersedia potensi lahan untuk pengembangan, memiliki harga jual produk yang baik, dan memiliki nilai ekonomi yang tinggi. Peningkatan pendapatan masyarakat dari usaha tani berdampak pada peningkatan tabungan dan konsumsi masyarakat yang tentunya akan meningkatkan pendapatan pemerintah (Siregar et al. 2008

Berdasarkan permasalahan diatas, penelitian ini bertujuan untuk: (1) menentukan lokasi pengembangan yang sesuai untuk perkebunan lada; (2) menganalisis kelayakan usaha perkebunan lada; (3) menganalisis marjin pemasaran dalam rantai pemasaran lada putih; (4) menganalisis kelembagaan pengusahaan lada; dan (5) menyusun arahan pengembangan perkebunan lada di Kabupaten Bangka Tengah.

Ruang lingkup penelitian ini dilakukan pada lahan aktual milik petani dan lahan-lahan potensial berdasarkan kesesuaian lahan dan kelayakan usaha di Kabupaten Bangka Tengah yang memungkinkan untuk dibudidayakan perkebunan lada. Batasan penelitian adalah untuk merekomendasikan lokasi lahan perkebunan lada dalam rangka menyusun arahan pengembangan perkebunan lada di Kabupaten Bangka Tengah Provinsi Kepulauan Bangka Belitung. 


\section{METODE PENELITIAN}

Penelitian dilakukan di Kabupaten Bangka Tengah Provinsi Kepulauan Bangka Belitung dari bulan Juli 2015 - Nopember 2015. Kabupaten ini mempunyai wilayah seluas 227.911,00 hektar dengan jumlah penduduk 162.525 jiwa. Berdasarkan data statistik Kabupaten Bangka Tengah dalam Angka pada tahun 2013, Kabupaten Bangka Tengah terdiri dari 6 kecamatan, serta 7 kelurahan dan 56 desa. Secara geografis, Kabupaten Bangka Tengah terletak pada $2^{\circ} 11^{\prime}$ Lintang Selatan sampai $2^{\circ} 46^{\prime}$ Lintang Selatan dan $105^{\circ} 48^{\prime}$ Bujur Timur sampai $106^{\circ} 51^{\prime}$ Bujur Timur (Gambar 1).

Data yang digunakan dalam penelitian ini berupa data primer dan sekunder. Data primer diperoleh dari hasil kuesioner dan wawancara mendalam kepada stakeholders. Penentuan responden penelitian menggunakan metode purposive sampling. Data sekunder berupa Peta Administrasi Kabupaten Bangka Tengah, Peta Tanah, Peta Penggunaan Lahan, RTRW Kabupaten Bangka Tengah 2011-2031, Peta Kawasan Hutan, Peta Kawasan Pertambangan, Data Perkebunan, dan Data Penduduk,. Metode analisis yang digunakan adalah analisis spasial untuk menentukan lokasi yang sesuai dan tersedia untuk perkebunan lada, analisis pendapatan petani dan kelayakan usaha tani, analisis rantai pemasaran, serta analisis deskriptif terhadap suatu objek dengan tujuan membuat deskripsi atau gambaran secara sistematis mengenai fakta-fakta yang sedang diteliti.

Data untuk analisis usaha tani dilakukan melalui pemilihan sampel petani secara sengaja (purposive sampling) yang diambil dari petani yang bermatapencaharian utama sebagai petani lada yang sudah berproduksi sekaligus pemilik kebun pada kelas kesesuaian lahan yang ditentukan sebelumnya. Dari kecamatan terpilih, diambil sampel desa yang memiliki luas kebun lada yang dominan.

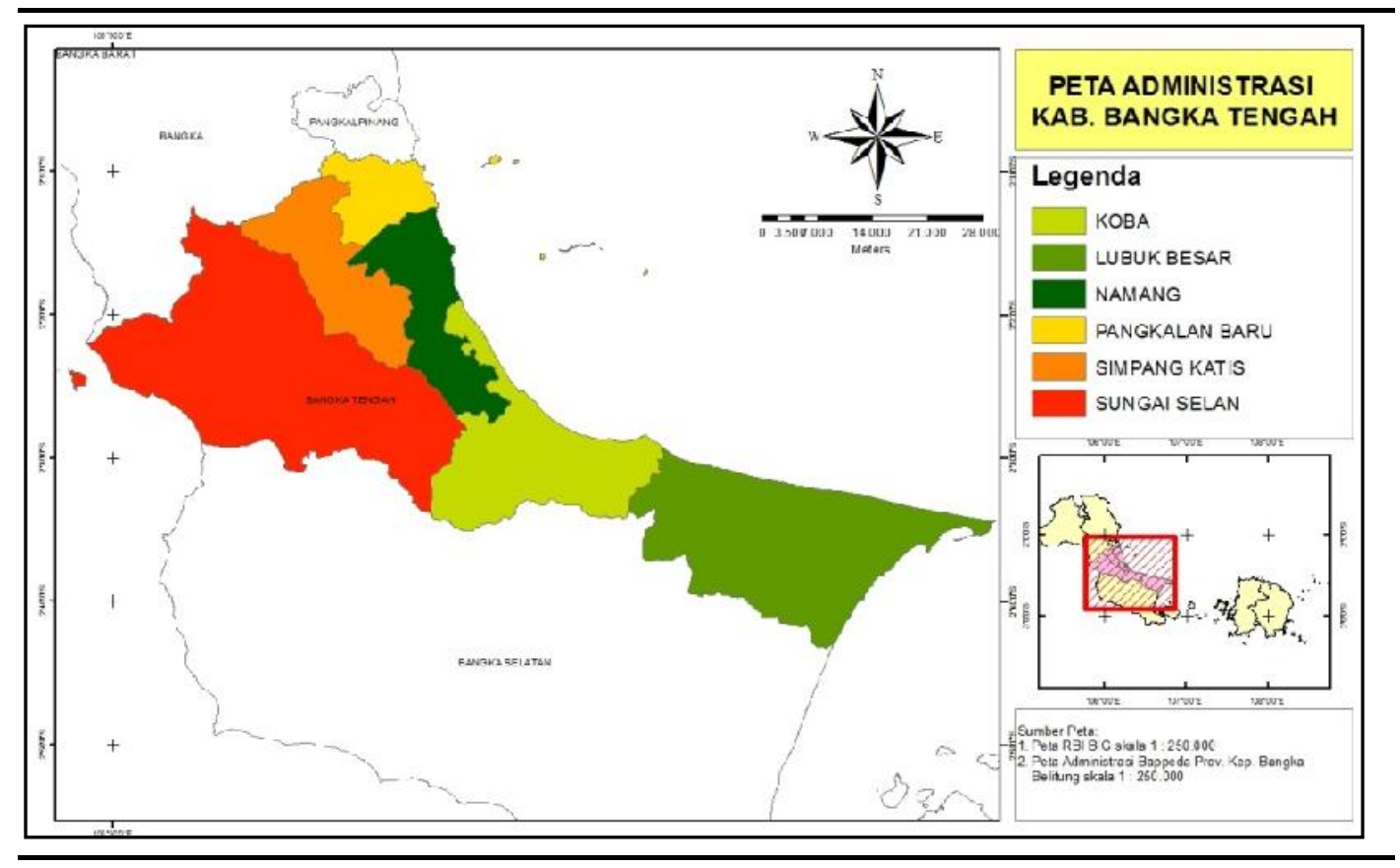

Gambar 2. Peta administrasi Kabupaten Bangka Tengah

Analisis pemasaran dihasilkan dari data pemilihan responden yang juga dilakukan secara sengaja. Hal ini untuk menghindari adanya pedagang pengumpul yang menjadi kaki tangan pedagang pengumpul di atasnya. Responden dipilih dari pedagang pengumpul lada 
putih mulai dari tingkat desa hingga eksportir. Pemilihan sampel sebanyak 2 pedagang pengumpul pada setiap tingkatan rantai pemasaran.

\section{HASIL DAN PEMBAHASAN}

\section{Persebaran Lokasi Potensial}

Dari peta kesesuaian lahan untuk tanaman lada tersebut diperoleh informasi bahwa sebagian besar lahan di Kabupaten Bangka Tengah sesuai (S) untuk tanaman lada yaitu seluas $212.709,01$ ha atau mencapai $99,74 \%$ dari luas lahan yang ada dan sisanya lahan yang tidak sesuai $(\mathrm{N})$ mencapai 553,4 ha $(0,3 \%)$. Secara aktual sebagian besar masuk dalam kelas sesuai marginal (S2) yaitu seluas $143.924,9$ ha $(65,2 \%)$,sedangkan yang masuk dalam kelas cukup sesuai (S3) seluas $70.012,0$ ha (34,5\%) untuk tanaman lada di Kabupaten Bangka Tengah. Secara spasial lokasi lahan dengan kelas kesesuaian lahan aktual disajikan pada Gambar 2. Luas masing-masing kecamatan di Kabupaten Bangka Tengah berdasarkan ordo kesesuaian lahan disajikan pada Tabel 1.
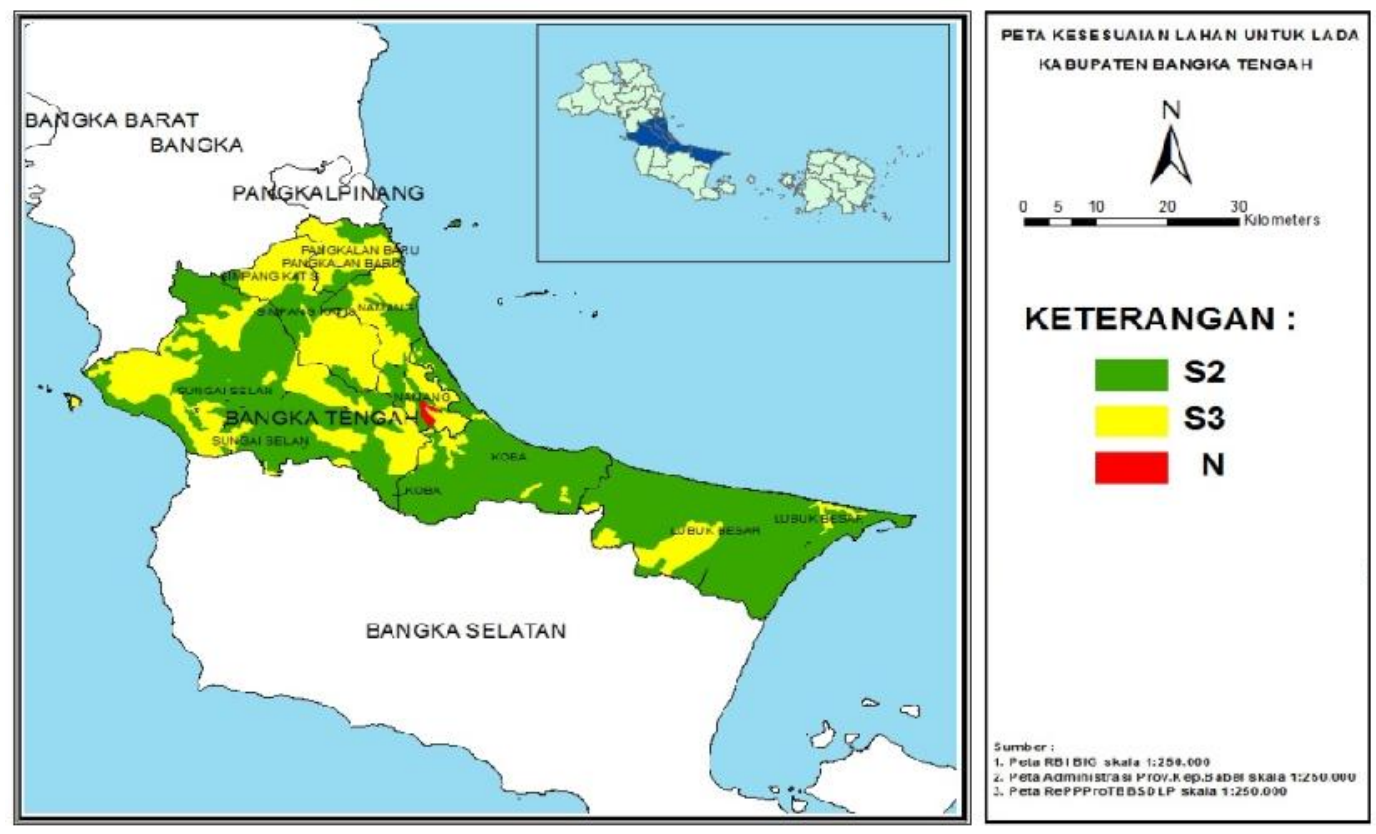

Gambar 3. Peta kesesuaian lahan untuk tanaman lada

Tabel 1. Luas kesesuaian lahan untuk tanaman lada di Kab. Bangka Tengah

\begin{tabular}{llrrr}
\hline \multirow{2}{*}{ No. Kecamatan } & \multicolumn{3}{c}{ Ordo Kesesuaian Lahan } \\
\cline { 3 - 5 } & & \multicolumn{1}{c}{ S2 } & S3 & $\mathrm{N}$ \\
\hline 1. & Koba & $31.180,1$ & $2.959,1$ & - \\
2. & Pangkalan Baru & $2.974,8$ & $7.528,0$ & - \\
3. & Sungai Selan & $49.647,2$ & $29.729,4$ & - \\
4. & Simpang Katis & $5.984,3$ & $16.383,6$ & - \\
5. & Namang & $7.331,1$ & $12.374,6$ & 553,4 \\
6. & Lubuk Besar & $46.807,4$ & $7.037,3$ & - \\
\hline & Jumlah & $143.924,9$ & $76.012,0$ & 553,4 \\
\hline
\end{tabular}




\section{Kelayakan Usaha Perkebunan Lada}

Asumsi yang digunakan dalam analisis ini bahwa produksi tanaman lada mulai berproduksi pada umur 3 tahun setelah tanam dan mengalami produksi maksimal pada 4 tahun setelah tanam dan akan terus menurun hingga umur 6 tahun. Analisis dilakukan dalam skala pengusahaan kebun seluas 1 (satu) hektar dan selama umur produktif tanaman lada yaitu sampai 6 tahun.

Tabel 2. Rata-rata pendapatan responden petani lada di Kabupaten Bangka Tengah

\begin{tabular}{|c|c|c|c|c|}
\hline Uraian & Satuan & $\begin{array}{c}\text { Harga } \\
\text { satuan (Rp) }\end{array}$ & Volume & Nilai (Rp) \\
\hline A. Penerimaan usaha tani & $\mathrm{Kg}$ & 132.000 & 989,3 & 130.587 .600 \\
\hline B. Biaya usaha tani & & & & 74.033 .500 \\
\hline B.1. Biaya tunai & & & & 63.033 .500 \\
\hline B.2. Biaya diperhitungkan & & & & 11.000 .000 \\
\hline C. Pendapatan atas biaya total (A-B) & & & & 56.554 .100 \\
\hline D. Pendapatan tunai (A-B1) & & & & 67.554 .100 \\
\hline E. $\quad R C$ atas biaya tunai $(A / B 1)$ & & & & 2,1 \\
\hline F. $\quad \mathrm{RC}$ atas biaya total $(\mathrm{A} / \mathrm{B})$ & & & & 1,8 \\
\hline
\end{tabular}

Nilai $R C$ ratio atas biaya tunai adalah 2,1 yang artinya setiap Rp 1 biaya tunai yang dikeluarkan oleh petani akan menghasilkan penerimaan sebesar $\mathrm{Rp} 2,1$. Apabila memasukkan biaya yang diperhitungkan dalam komponen biaya total, maka nilai $R C$ Ratio menjadi 1,8 yang berarti setiap Rp 1 biaya yang dikeluarkan akan memperoleh penerimaan sebesar Rp 1,8. Nilai $R C$ ratio yang lebih dari satu menunjukkan bahwa usaha tani lada di Kabupaten Bangka Tengah masih menguntungkan.

Pada Tabel 3 dapat menunjukkan bahwa lahan S2 memiliki BEP volume produksi lebih rendah dari lahan S3, demikian pula dengan nilai $B C$ Ratio lahan S2 lebih tinggi dari lahan S3. Secara umum kedua kelas lahan layak untuk pengembangan perkebunan lada.

Tabel 3. Analisis kelayakan usaha perkebunan lada rakyat di Kab. Bangka Tengah

\begin{tabular}{llcrrrl}
\hline No. & Kecamatan & $\begin{array}{c}\text { Kelas } \\
\text { Kesesuaian }\end{array}$ & $\begin{array}{r}\text { BEP } \\
\text { Produksi(kg) }\end{array}$ & $\begin{array}{r}\text { BEP } \\
\text { Harga(Rp) }\end{array}$ & BC Ratio & $\begin{array}{l}\text { Payback } \\
\text { Period(th) }\end{array}$ \\
\hline 1. & Sungai Selan & S2 & 994,6 & 41.695 & 3,3 & 4,2 \\
2. & Namang & S2 & 903,2 & 31.587 & 4,4 & 4,1 \\
3. & Lubuk Besar & S2 & $1.067,4$ & 40.041 & 3,5 & 4,2 \\
4. & Koba & S3 & $1.681,6$ & 90.905 & 1,5 & 4,8 \\
5. & Pangkalan Baru & S3 & $1.101,3$ & 65.009 & 2,1 & 4,4 \\
6. & Simpang Katis & S3 & $1.393,1$ & 66.820 & 2,1 & 4,5 \\
\hline
\end{tabular}

Hasil analisis sensitivitas pada 3 skenario yang diterapkan (dengan asumsi variabel lain ceteris paribus) ditampilkan pada Tabel 4.

Tabel 4. Analisis sensitivitas usaha tani lada pada 3 skenario yang diterapkan.

\begin{tabular}{|c|c|c|c|c|c|c|c|c|}
\hline \multirow[t]{2}{*}{ No } & \multirow[t]{2}{*}{ Kecamatan } & \multirow[t]{2}{*}{$\begin{array}{c}\text { Kelas } \\
\text { kesesuaian } \\
\text { lahan }\end{array}$} & \multicolumn{2}{|c|}{$\begin{array}{c}\text { Penurunan } \\
\text { produksi } 30 \%\end{array}$} & \multicolumn{2}{|c|}{$\begin{array}{c}\text { Peningkatan biaya } \\
\text { bibit } 50 \%\end{array}$} & \multicolumn{2}{|c|}{$\begin{array}{c}\text { Penurunan harga } \\
\text { jual } 20 \%\end{array}$} \\
\hline & & & $B C R$ & PBP(th) & $B C R$ & PBP(th) & $B C R$ & PBP(th) \\
\hline 1. & Sungaiselan & S2 & 2,3 & 4,4 & 3,2 & 4,3 & 2,7 & 4,3 \\
\hline 2. & Namang & S2 & 3,1 & 4,2 & 4,2 & 4,1 & 3,5 & 4,2 \\
\hline 3. & Lubuk Besar & S2 & 2,4 & 4,4 & 3,3 & 4,2 & 2,8 & 4,3 \\
\hline 4. & Koba & S3 & 1,0 & 5,6 & 1,4 & 5,1 & 1,2 & 5,4 \\
\hline 5. & Pangkalan Baru & S3 & 1,4 & 4,8 & 1,9 & 4,5 & 1,7 & 4,6 \\
\hline 6. & Simpang Katis & S3 & 1,5 & 5,1 & 1,7 & 4,8 & 1,8 & 4,7 \\
\hline Nete & BCR & $=$ Benefit $\mathrm{Cc}$ & Ratio & PBP & $=\mathrm{Pa}$ & Period & & \\
\hline
\end{tabular}


Ketiga skenario yang dijadikan dasar perhitungan analisis sensitivitas memberikan hasil yang layak untuk tetap melanjutkan usaha perkebunan lada. Skenario yang dilakukan hanya mengurangi manfaat (keuntungan) yang diperoleh cukup signifikan dibandingkan dengan kondisi normal.

\section{Efisiensi Rantai Pemasaran Lada Putih}

Pemasaran komoditi lada putih di daerah penelitian memiliki 3 saluran penelitian, yaitu: rantai pemasaran I (petani-pedagang pengumpul desa-pedagang pengumpul kecamatan-eksportir), rantai pemasaran II (petani-pedagang pengumpul kecamataneksportir), dan rantai pemasaran III (petani-eksportir). Berdasarkan hasil yang ditampilkan pada Tabel 4, rantai pemasaran III lebih menguntungkan dengan persentase farmer's share 90,86\% dan marketing margins $9,14 \%$.

Perhitungan profitability index menunjukkan bahwa keuntungan eksportir lebih tinggi dibandingkan lembaga pemasaran lain (sal.I=4,67\%; sal.II=3,25\%; sal.III=2,60). Hal ini lebih disebabkan eksportir bebas menentukan harga.

Tabel 4. Matriks keragaan pemasaran lada putih di Kabupaten Bangka Tengah

\begin{tabular}{|c|c|c|c|}
\hline No. & Jenis analisis & Rantai pemasaran & Nilai (per kg) \\
\hline 1. & $\begin{array}{l}\text { Bagian harga yang } \\
\text { diterima petani }\end{array}$ & $\begin{array}{l}\text { Saluran I } \\
\text { (Petani-PPD-PPK-Eksportir) } \\
\text { Saluran II } \\
\text { (Petani-PPK-Eksportir) } \\
\text { Saluran III } \\
\text { (Petani-Eksportir) }\end{array}$ & $\begin{array}{l}\text { Rp } 173.000 \\
87,82 \% \\
\text { Rp } 176.000 \\
89,34 \% \\
\text { Rp } 179.000 \\
90,86 \%\end{array}$ \\
\hline 2. & Marjin pemasaran & $\begin{array}{l}\text { Saluran I } \\
\text { (Petani-PPD-PPK-Eksportir) } \\
\text { Saluran II } \\
\text { (Petani-PPK-Eksportir) } \\
\text { Saluran III } \\
\text { (Petani-Eksportir) }\end{array}$ & $\begin{array}{l}\text { Rp } 24.000 \\
12,18 \% \\
\text { Rp } 21.000 \\
10,66 \% \\
\text { Rp } 18.000 \\
9,14 \%\end{array}$ \\
\hline
\end{tabular}

\section{Arahan Pengembangan Perkebunan Lada}

Lahan yang berpotensi yang tersedia untuk pengembangan tanaman lada di Kabupaten Bangka Tengah tersebar pada 6 kecamatan dengan luasan 28.151,8 ha. Kecamatan dengan lahan berpotensi terluas adalah Kecamatan Sungai Selan dengan luasan $8.370,9$ ha $(29,7 \%)$, kemudian diikuti oleh Kecamatan Simpang Katis dan Kecamatan Namang dengan masing-masing luas lahan $8.257,8$ ha $(29,3 \%)$ dan $6.539,8$ ha $(23,2 \%)$.

Tabel 5. Luas arahan lokasi pengembangan lada di Kabupaten Bangka Tengah

\begin{tabular}{llrrrrrr}
\hline \multirow{2}{*}{ No. } & \multirow{2}{*}{ Kecamatan } & \multicolumn{1}{c}{$\begin{array}{c}\text { Bukan } \\
\text { arahan }\end{array}$} & \multicolumn{6}{c}{\begin{tabular}{c} 
Lahan arahan \\
\cline { 3 - 7 }
\end{tabular}} & Prioritas I & Prioritas II & Prioritas III & Prioritas IV & Jumlah \\
\hline 1 & Sungai Selan & $59.049,6$ & $6.642,8$ & 630,0 & 547,9 & 550,2 & $8.370,9$ \\
2 & Koba & $28.752,9$ & $4.317,9$ & - & 14,8 & - & $4.332,7$ \\
3 & Lubuk Besar & $48.925,5$ & 334,5 & - & 283,1 & 1,6 & 619,2 \\
4 & Simpang Katis & $12.128,0$ & 252,7 & 147,8 & $7.828,8$ & 28,5 & $8.257,8$ \\
5 & Namang & $13.701,4$ & 180,8 & 45,5 & $6.313,5$ & - & $6.539,8$ \\
6 & Pangkalan Baru & $8.449,5$ & 11,7 & 19,7 & - & - & 31,4 \\
\hline & Jumlah & $171.006,9$ & $11.740,4$ & 843,0 & $14.988,1$ & 580,3 & $28.151,8$ \\
\hline
\end{tabular}




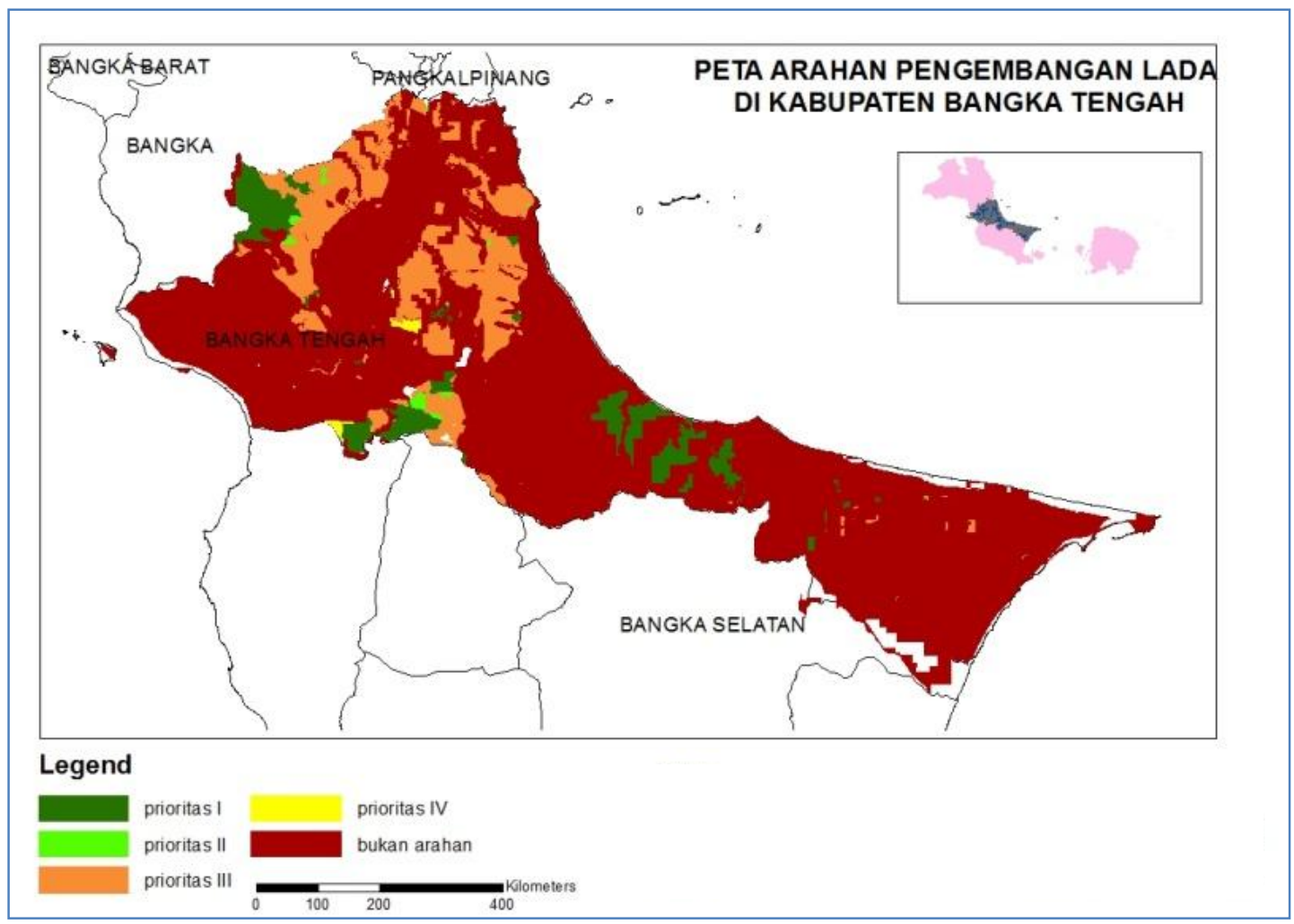

Gambar 4. Peta arahan pengembangan lada di Kab. Bangka Tengah

Prioritas I dan prioritas II hanya dibedakan oleh kelas lahan S2 untuk prioritas I dan S3 untuk prioritas II dengan tipe penggunaan lahan yang sama berupa semak belukar dan perkebunan. Prioritas III dan IV dengan kelas lahan S2 dan S3 dan dibedakan oleh tipe penggunaan lahan pertanian lahan kering untuk prioritas III dan Areal Penggunaan Lain (APL) untuk prioritas IV.

Pengembangan usaha tani lada di Kabupaten Bangka Tengah dapat diarahkan ke lahan arahan pengembangan yang telah dibuat seluas $28.151,8$ ha dengan prioritas pengembangan seperti pada Tabel 5 yang secara spasial ditampilkan pada Gambar 3. Hasil tersebut perlu disosialisasikan oleh pemerintah agar masyarakat mengetahui lokasi arahan pengembangan perkebunan lada.

\section{KESIMPULAN}

Berdasarkan hasil pembahasan, dapat disimpulkan bahwa sebagian besar lahan di Kabupaten Bangka Tengah sesuai untuk budidaya tanaman lada yaitu lahan S2 seluas 143.924,9 ha dan S3 seluas 76.012,0 ha dan dari hasil analisis pendapatan petani dan kelayakan usaha masih menguntungkan untuk tetap dilakukan pengembangan perkebunan lada. Kinerja pemasaran komoditi lada putih relatief efisien yang diindikasikan dari perhitungan parameter marketing margins, farmer's share, dan profitability index. Menindaklanjuti beberapa analisis tersebut, pengusahaan perkebunan lada masih sangat memungkinkan untuk dilanjutkan dengan areal arahan pengembangan seluas $28.151,8$ ha 
yang tersebar di semua kecamatan dengan lebih memprioritaskan Kecamatan Sungai Selan dengan luas arahan 8.370,9 ha.

Pemerintah Kabupaten Bangka Tengah perlu segera merealisasikan rencana pembangunan pabrik pengolahan lada putih atau mendatangkan investor mengingat ketersediaan bahan baku yang cukup besar yang tentunya akan berimplikasi pada peningkatan perekonomian daerah. Hal tersebut perlu dilakukan sebagai antisipasi menurunnya harga lada putih di pasar internasional yang terintegrasi ke pasar domestik. Selain itu, lebih meningkatkan lagi peran para penyuluh dan mengaktifkan kelompokkelompok tani di masyarakat untuk meningkatkan kuantitas dan kualitas lada yang dihasilkan dan meningkatkan bargaining position petani dalam pemasaran lada dan mengarahkan petani lada pada penggunaan varietas lada dengan produktivitas tinggi serta memiliki ketahanan terhadap penyakit kuning.

\section{DAFTAR PUSTAKA}

Daras U, Pranowo D. 2009. Kondisi Kritis Lada Putih Bangka Belitung dan Alternatif Pemulihannya. Jurnal Penelitian dan Pengembangan Pertanian 28(1):1-6.

Djakapermana RD. 2010. Pengembangan Wilayah:Melalui Pendekatan Kesisteman. Bogor (ID): IPB Press.

Djulin A, AH Malian. 2006. Struktur dan Integrasi Pasar Ekspor Lada Hitam dan Lada Putih di Daerah Produksi Utama. Jurnal Penelitian Tanaman Industri 7(4): 113-119.

Indraningsih, KS. 2013. Faktor-faktor yang mempengaruhi Kinerja Usaha Tani Sebagai Representasi Strategi Penyuluhan Pertanian Berkelanjutan di Lahan Marjinal. Jurnal Agro Ekonomi 31(1): 71-95.

Kemala, S. 2011. Strategi Pengembangan Sistem Agribisnis Lada untuk Meningkatkan Pendapatan Petani. Jurnal Pengembangan Inovasi Pertanian 4(2): 137-155.

Evalia NA, EG Said, RN. Suryana. 2012. Strategi Pengembangan Agroindustri dan Peningkatan Nilai Tambah Gambir di Kabupaten Lima puluh Kota. Jurnal Manajemen dan Agribisnis 9(3): 173-182.

Kemala S. 2011. Strategi Pengembangan Sistem Agribisnis Lada untuk Meningkatkan Pendapatan Petani. Bogor (ID): Balai Penelitian Tanaman Obat dan Aromatik. Jurnal Pengembangan Inovasi Pertanian. 4(2): $137-155$

Pranoto, YS. 2011. Dampak Kebijakan Pemerintah Terhadap Keuntungan dan Daya Saing Lada Putih (Muntok White Pepper) di Provinsi Bangka Belitung [Tesis]. Bogor: Sekolah Pascasarjana, Institut Pertanian Bogor.

Rustiadi E, S Saefulhakim, DR Panuju. 2011. Perencanaan dan Pengembangan Wilayah. Jakarta (ID): Crestpent Press dan Yayasan Pustaka Obor Indonesia.

Saefudin. 2014. Tantangan dan Kesiapan Teknologi Penyediaan Bahan Tanam Mendukung Peningkatan Produktivitas Nasional Tanaman Lada (Piper nigrum L). Bogor(ID): Jurnal Perspektif. 13(2): 111-125.

Setianto P dan I Susilowati. 2014. Komoditas Perkebunan Unggulan yang Berbasis pada Pengembangan Wilayah Kecamatan di Kabupaten Banjarnegara Provinsi Jawa Tengah. Jurnal Wilayah dan Lingkungan 2(2): 143-156.

Siregar H, Widyastutik, H. Mulyati. Usaha Kecil Lidah Buaya di Kabupaten Bogor: Sebuah Analisis Sosial, Ekonomi dan Lingkungan. Jurnal Manajemen dan Agribisnis 5(1): 33-39.

Yuhono, JT. 2007. Sistem Agribisnis Lada dan Strategi Pengembangannya. Jurnal Penelitian dan Pengembangan Pertanian 26(2): 76-81. 